\title{
Coalescence of Water Drops in Water-ULSD Dispersions via Electrowetting
}

\author{
Ashish Bandekar and George G. Chase*
}

Department of Chemical and Bio-Molecular Engineering, The University of Akron, Akron, OH 44325, USA

\begin{abstract}
Coalescence of water droplets is an important phenomenon in many industrial applications. One approach for coalescing water droplets is by applying an external voltage across the drops. Coalescence occurs when spreading and motion of the drops due to the electrical field brings the drops into contact. Electrowettable surfaces were prepared with poly(styrene-co-methyl methacrylate) as the dielectric film and Fluropel ${ }^{\mathrm{TM}}$ as the hydrophobic surface layer. The surface of a stainless steel disk was coated in a way that the dielectric coating layer thickness varied with radial position with minimum thicknesses at the center and at the outer edge of the disk and a maximum at an intermediate radial position of the disk surface. The thickness gradient influenced the droplet movement and contributed to the coalescence. Two disks were assembled with a thin slit between the disks. Emulsions of water droplets in ultra low sulfur diesel fuel were pumped through the thin slit. Experiments showed significant increase in drop sizes when the disks were electrified compared to non-electrified disks.
\end{abstract}

Received on 29-03-2016 Accepted on 14-04-2016 Published on 24-05-2016

Keywords: Electrowetting, Coalescence, Emulsion, Dispersion, Oil-Water Separation.

\section{INTRODUCTION}

Water contamination in ultra low sulfur diesel (ULSD) fuels adversely affects engine performance and can damage sensitive engine parts. Water commonly enters the fuels in vehicle fuel tanks through various mechanisms including condensation from humid air, precipitation entering tank openings, and others. Fuels may contain small concentrations of dissolved water and amounts of water above the maximum solubility that often resides as dispersed droplets in the fuel.

Separation of water droplets larger than about 100 microns from the fuels can be effectively and economically done using gravity and common inertial separators. Droplets smaller than 100 microns are often more difficult to separate and require alternative techniques. Ideally the separation method should not significantly impact the engine performance by requiring significant power (rate of energy) to operate thus decreasing the power extracted from the fuel to drive the engine and vehicle.

Coalescing filters, absorbers, and water rejecting membranes are often applied to increase drop sizes to make them easier to separate downstream before the fuel enters the engine [13]. All of the methods have advantages and disadvantages.

"Department of Chemical and Bio-Molecular Engineering, The University of Akron, Akron, OH 44325, USA; Tel: 330.972.7943;

E-mail: gchase@uakron.edu
Often the separators work more effectively on larger drops. These processes can be coupled with devices that coalesce (enlarge) the drops to improve separation of smaller drops. The aim of this work is to apply electrowetting (EW) to coalesce water drops in ULSD.

In general, the rate of coalescence of droplets in a dispersion depends on the concentration of drops per volume of fluid. The rate of collisions between drops increases as the drop concentration increases and the rate of coalescence increases.

Electric fields can be used to promote coalescence by increasing the attractive force between the droplets and thus increase the droplet concentration [4-9]. Coalescence of two suspended water drops submerged in ULSD requires the drops to come into contact. A thin film of ULSD separates the droplets for the drops to exist as separate distinct structures. If the droplets remain in contact (separated by the ULSD film) for a sufficient length of time, the thickness of the ULSD film gradually reduces due to attractive forces between the molecules of each drop until the ULSD film ruptures and the droplets coalesce to form one drop [10]. Water Droplets on surfaces can be affected by thin films of water spread across the surface that can aid in rupturing the ULSD film between drops. Once the ULSD film between drops is ruptured the coalescence occurs very rapidly (on the order of $10^{-4} \mathrm{~s}$ in the case of drops on fibers) [11]. 
The rate of coalescence of drops is also enhanced by a difference in speed of the two phases of the dispersion [12]. The electric field in EW can increase attraction between drops and it can slow the movement of drops relative to the flowing ULSD.

EW was introduced by Lippmann in 1875 [13]. EW modifies the effective contact angle of drops on surfaces [14]. EW uses a hydrophobic dielectric coating that holds electric charge proportional to the coating thickness on an electrode surface. When charged, the electrical forces cause the contact angle of drops on the surface to decrease compared to uncharged droplets [14]. Techniques have been reported to make electrowetted drops move across surfaces due to imbalanced forces acting on the drops parallel to the surface, such as by a spatial gradient in the dielectric coating or by using an array of electrodes that are alternately electrified [15-18].

EW manipulates the contact force between a conductive droplet and a surface by application of an electric field without changing the intrinsic material surface tension. EW induces charges on the surfaces of a conducting droplet (water droplet) and a non-conducting dielectric insulated surface, which couples with the surface tension force to cause a contact angle change [19-21]. In an oil environment, EW can provide more than 100 deg of contact angle modulation reversibly, with high fast response to actuation [22] and as a result EW can be used in various lab-on-chip devices [23], as variable focus lenses [24] and in electronic displays [25].

The force between a drop and a surface is proportional to the length of the contact line [26]. The length of the contact line increases when the contact angle decreases for a drop on a surface, as it does in EW. Hence the normal force holding a drop to a surface is larger for an electrowetted drop than for an uncharged drop. From fluid mechanics, as the normal force increases the friction drag tends to increase. This means that if a drop is dragged across a surface due to flowing ULSD fuel, then through electrification, the drop will slow down or stop moving. The slowed or stopped movement of a cloud of drops increases the droplet concentration and increases the rate of drop-drop collisions and coalescence. As the drop gets larger the drag force of the flowing ULSD increases faster than the force of the contact line. Eventually the drag force of the flowing ULSD exceeds the surface forces holding the drops stationary and the drops move again.

\section{EXPERIMENTAL PREPARATION}

\subsection{Dielectric Solution Preparation}

A $15 \mathrm{wt} / \mathrm{wt} \%$ solution of poly(styrene-co-methyl methacrylate) (PS/PMMA, Aldrich, MW: 100,00 150,000) was prepared by dissolving PS/PMMA in toluene (ACS reagent $\geq 99.5 \%, \mathrm{MW}$ : $92.14 \mathrm{~g} / \mathrm{mol})$. The solution was mixed at $200 \mathrm{rpm}$ using an orbital shaker for 24 hours at room temperature, to completely dissolve the PS/PMMA particles. The solution was stored in glass bottle at room temperature. The solution used for the hydrophobic coating layer was the commercial polymer Fluropel $^{\mathrm{TM}} 1601 \mathrm{~V}$ (Cytonix, Maryland) [27]. The Fluropel $^{\mathrm{TM}}$ was used as supplied without further modification.

\subsection{Coating Technique}

A technique to coat the stainless steel discs was developed that produced gradients in the thickness of the dielectric layers. The discs were coated by PS/PMMA and Fluropel ${ }^{\mathrm{TM}}$ in the same manner. Figure 1 shows a schematic of the custom-made dip-coating apparatus. The center of the stainless steel disc was attached to the shaft of a motor that controlled the rotation rate of the disc. The motor was attached to a glide on rails. The vertical position of the glide was controlled by a thin plastic line attached to a take-up reel connected to a second motor. A second motor controlled the rate that the plastic line was wound or unwound from the reel and hence controlled the rate of vertical movement.

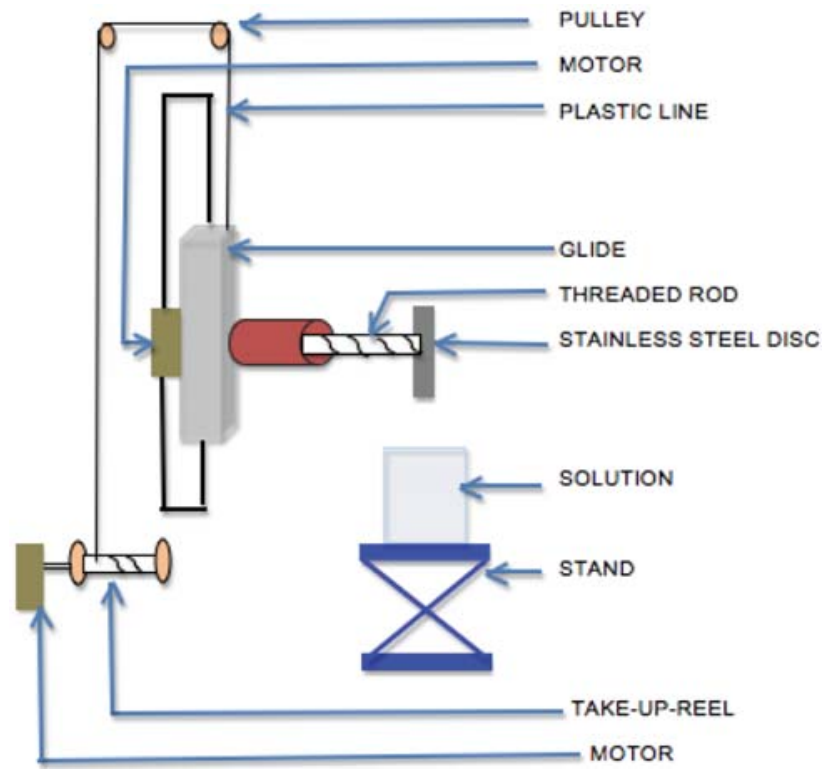

Figure 1: Schematic of the experimental setup for coating the discs.

Each disc was first coated with the dielectric polymer. During coating, the disc was rotated around its axis and at the same time it moved downward or upward. While rotating, the disc was lowered into the coating solution until it was immersed to the center of the disc. The disc was rotated while half submerged in the coating solution for specific immersion time, and then it was withdrawn by upward motion. The disc was dried in air with the coated surface faced upward. The coating process was repeated with the hydrophobic layer polymer. The discs were air dried for at least one day after each coating.

The rotation rate of the disc, the dielectric polymer concentration, and the immersion time were studied to evaluate their effects on the electrowetting voltage required to cause a water drop to move on the disc surface. To coalesce 


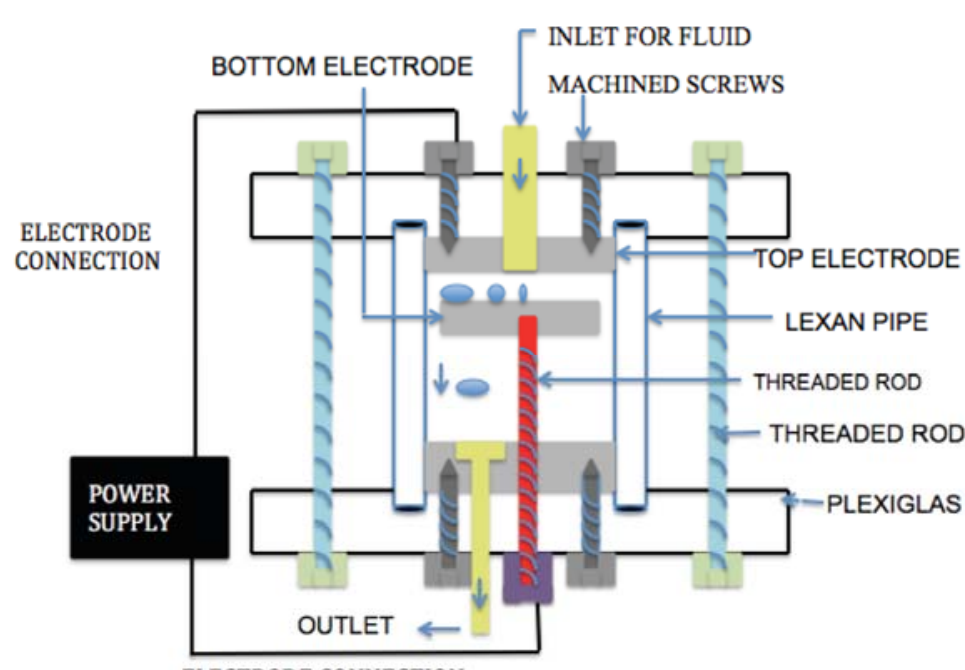

ELECTRODE CONNECTION

Figure 2: Schematic design of electrowet-coalescer device.

drops in a electrowet-coalescer device our aim was to fabricate coatings that resulted in drop movements at a low applied electric potential voltage.

\subsection{Electrowet-Coalescer Device}

A schematic of the electrowet-coalescer device is shown in Figure 2. The water-ULSD dispersion entered at the top, flowed through a narrow slit between the electrodes and exited through the outlet. The electric potential difference was applied between the electrodes by wire connections to the screws and rod holding the coated discs.

The bottom disc was attached to a threaded rod for setting the distance between the two electrode discs. The gap between the electrodes was set at $0.001 \mathrm{~m}$ but could be varied in future experiments. The outer wall was a transparent non-conductive Lexan cylindrical tube. The Lexan tube was capped with Plexiglas ends that sealed the assembly and provided support for the remaining parts. The top electrode was attached to the top Plexiglas cap with machine screws. The whole assembly was held together by threaded rods.

The diameter of the top disc was $0.0480 \mathrm{~m}$ and that of the disc on the threaded rod was $0.0355 \mathrm{~m}$. The inner diameter of the Lexan tube was $0.0482 \mathrm{~m}$ and its length was $0.100 \mathrm{~m}$

\subsection{Coalescence Experiment}

The electrowet-coalescer device was tested in the apparatus shown in Figure 3. Emulsion samples were taken at points

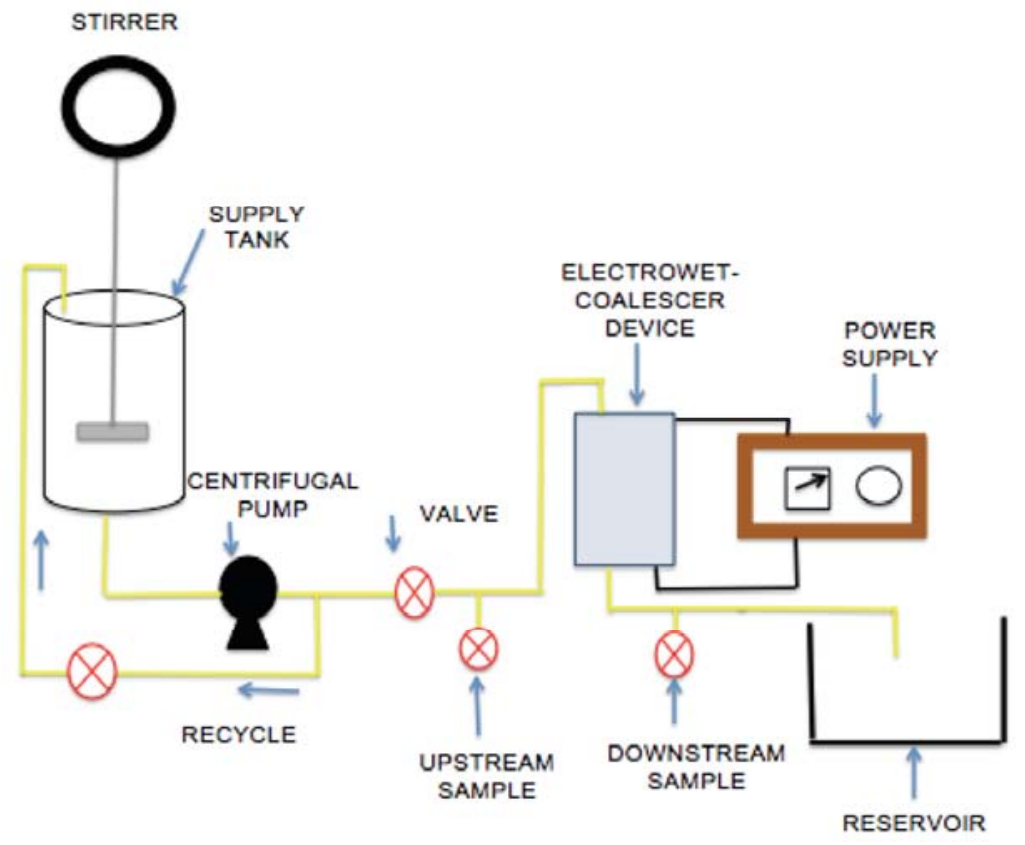

Figure 3: Water-ULSD flow system setup for testing the coalescer device. 


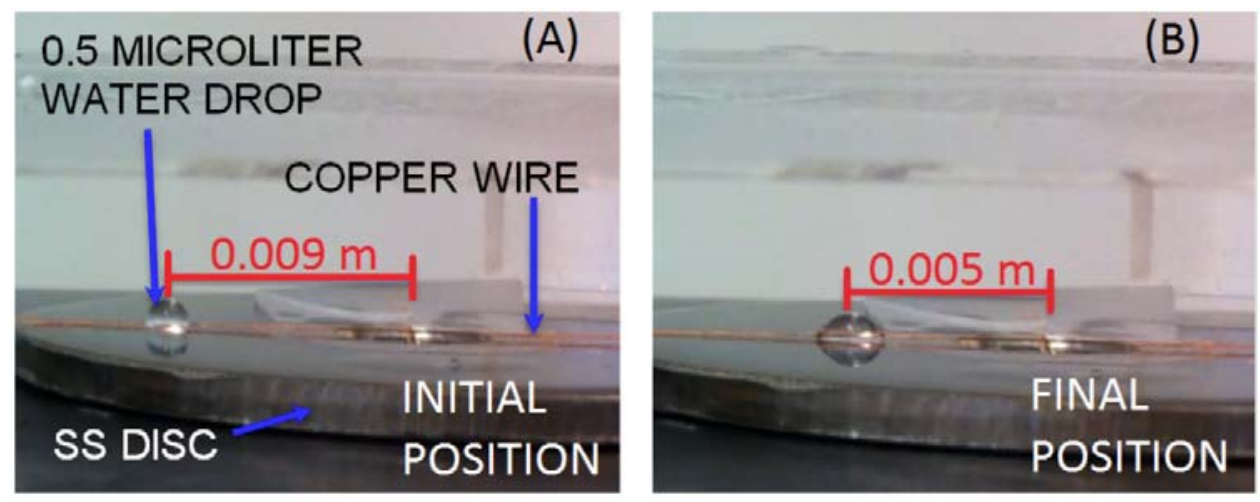

Figure 4: Photograph of a 0.5 microliter drop $(\mathbf{A})$ initially at radial position $0.009 \mathrm{~m}$ from center of the disc, and (B) after the drop moved to position $0.005 \mathrm{~m}$ from the center of the disc when a potential of $160 \mathrm{~V}$ volts was applied between the horizontal copper wire electrode and the disc. The disc surfaces were coated using the conditions of $15 \mathrm{sec}$ immersion times, 7.2 RPM rotation rates, and 15wt/wt\% dielectric solution concentrations. The distances between the copper wire and the surface of the disc was $0.0005 \mathrm{~m}$.

upstream and downstream from the coalescer to compare drop size distributions. Three gallons of ULSD was mixed with 27 milliliters of water for each run to produce a water concentration in the ULSD to simulate a water concentration typical of real applications. As the pump maintained a continuous flow of the ULSD through the recycle line it sheared the drops thereby breaking them into a size range below 100 microns. ULSD samples taken upstream and downstream were evaluated using a particle counter (Accusizer 780/SIS, Particle Sizing Systems Port Richey, FL, USA) to determine the drop size distributions at times 20,40, and 60 minutes into the experiments. Electric potential was supplied by a power supply (Model IP 17, Heathkit Regulated High Voltage Power Supply, Benton Harbor, Michigan).

\section{RESULTS AND DISCUSSIONS}

\subsection{Preparation of the Coated Discs}

A number of parameters affected the coating and the drop dynamics. The parameters and their ranges considered in this work were immersion time (10 to $60 \mathrm{~s}$ ), rotation rate of the disc (1.8 to 12 RPM), dielectric concentration (5 to 25 wt/wt \%), and drying time (1 to 3 days). These parameters interacted in complex ways that affected the thickness of the coatings. A thorough investigation of these parameters would be useful but was outside of the scope of the current work. The parameters were varied one at a time in a limited set of experiments to find conditions that provided surfaces that were sufficient for electrowetting so that the electrowetcoalescer device could be evaluated. A systematic investigation of these parameters is recommended for future work.

The coatings on the disc surfaces were not expected to have uniform thicknesses due to the coating method. By trial and error it was found that the drops initially positioned at $0.009 \mathrm{~m}$ from the center of the disc moved when sufficient potential was applied to the electrodes. For comparison between the coating parameters this initial position was used in all of the experiments to observe the drop motions.
Experiments were conducted to vary one parameter at a time in the sequence of immersion time, rotation rate, and dielectric solution concentration to determine the minimum electric potential required to cause movement of a water drop. The drying time of 1 day was used in all of these experiments. The effects of drying time are discussed later. The condition of minimum potential determined for one parameter was used in the subsequent parameter evaluations in the sequence of parameter experiments.

Drop movement was observed by placing a 0.5 microliter drop of water $0.009 \mathrm{~m}$ from the center of the coated disc. A horizontal copper wire was placed in contact with the top of the drop as shown in the photographs in Figure 4. The electric power was supplied by Quad Tech programmable DC power supply (Model- 42012-600-8, Chroma Systems Solutions, Massachusetts). The potential difference was gradually increased between the disc and the wire until the drop was observed to move. Figure 4A shows a drop in its initial position and Figure 4B shows the same drop $0.4 \mathrm{~cm}$ closer to the center of the disc after the drop moved due to the applied potential.

The immersion times were evaluated while holding constant the rotation rate at 12 RPM, and the concentration PS/PMMA at $5 \mathrm{wt} / \mathrm{wt} \%$. The potentials for several immersion times are listed in Table 1. The least potential was for immersion times of $15 \mathrm{~s}$. Discs used in the subsequent experiments were coated using $15 \mathrm{~s}$ immersion times.

Table 1: Summary of immersion time and the potential required for drop movement. In these experiments the rotation rate was 12RPM, the dielectric solution concentration was $5 \%$, and the drying times were one day

\begin{tabular}{|c|c|}
\hline Immersion time (sec) & Potential at which the dropsmoved (V) \\
\hline \hline 15 & $295-300$ \\
\hline 30 & $300-310$ \\
\hline 60 & $320-330$ \\
\hline
\end{tabular}


The effects of rotation rates are plotted in Figure 5. As the rotation rates were varied from 1.8 to 12 RPM a minimum in the potential required for drop movement occurred at rotation rate of 7.2 RPM. This rotation rate was used in subsequent experiments.

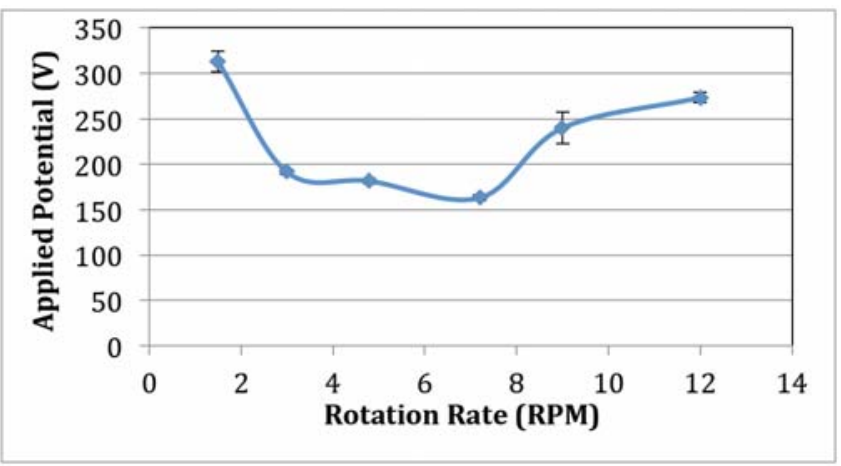

Figure 5: Applied potentials that caused drop movements for surfaces coated at different rotation rates. In these experiments the surfaces were coated at immersion times of $15 \mathrm{sec}$, the dielectric solution concentrations of $15 \%$ and the drying times of one day.

The effects of the dielectric solution concentrations on the electric potential are plotted in Figure 6 . The recipes were prepared by varying the $\mathrm{wt} / \mathrm{wt} \%$ of PS/PMMA to toluene and the solutions were mixed in an orbital shaker for 24 hours at $27^{\circ} \mathrm{C}$ prior to coating the discs. The least potential of $160 \mathrm{~V}$ occurred for solutions of $15 \mathrm{wt} / \mathrm{wt} \%$ PS/PMMA.

Also shown in Figure 6 are the corresponding coating thicknesses for each PS/PMMA at radial position $0.009 \mathrm{~m}$ from the center of the disc. Thicknesses were measured using an Elcho meter 456 (Model Elcho meter 456 S, Elcho meter Limited, Manchester, United Kingdom). The accuracy of the thickness measurement was about $\pm 5 \%$. The thickness measurements were taken at different angular positions on the disc and averaged over 10 readings. The standard deviation was 0.8 microns.

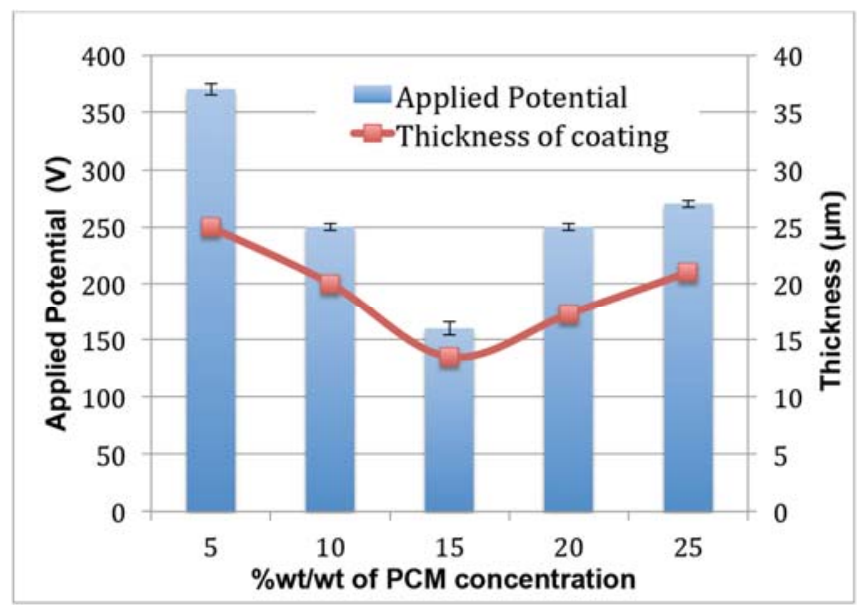

Figure 6: Electric potentials for drop movements and thicknesses of coatings prepared from PS/PMMA solutions of concentrations ranging from 5 to $25 \mathrm{wt} / \mathrm{wt} \%$. The coatings were prepared with rotation rates of 7.2 RPM and immersion times of $15 \mathrm{sec}$. The drying times were one day.
Figure 7 shows a plot of the coating thicknesses at the different radial positions. The radial variations in thickness were due to the dynamics of the coating process and solvent evaporation rate and its explanation is outside the scope of this work. The coating thicknesses on the discs where measured at three radial positions on each disc after drying for one day to determine the variation in coating thickness with position. At least 10 measurements were taken at different angular positions for each radius and averaged. The error bars show one standard deviation of the measurement.

The gradient in the coating thickness caused the electrically charged water drops to move in the direction of smaller coating thickness when sufficient potential was applied. The drop movements were probably due to imbalances in the surface forces acting on the drops due to spatial variations in the surface charges resulting from spatial variations in the dielectric coating thicknesses. This topic needs further investigation to verify the underlying mechanism.

Figure 8 shows the changes in coating thicknesses with drying times from one to three days. The coating thicknesses decreased with time, possibly as residual solvent evaporated. The changes in thicknesses between two and three days were very small and for practical purposes the coating thicknesses became constants after three days.

\subsection{Performance of the Electrowet-Coalescer}

The objective of the coalescence experiments was to increase the water drop sizes in the flowing ULSD by passing the ULSD emulsion through the electric field between two charged discs was to show the electrowet-coalescer could significantly change the drop size distribution towards larger drops, indicating significant coalescence occurred. The hydrophobic and dielectric coatings on the discs were applied for the conditions described above that resulted in the electric potential of 160 volts for drop movement. The discs were assembled into the electrowet-coalescer shown in Figure 2. Experiments were run by applying the potential as a square wave with $60 \mathrm{~s}$ potential-on followed by $60 \mathrm{~s}$ potential-off. A blank test was run in which the ULSD emulsion passed through the electrowet-coalescer with zero applied potential, to determent whether the flow through the device had an effect on the drop size distribution. The flow rate was maintained at $4 \mathrm{ml} / \mathrm{sec}$ throughout the experiment and the gap distance between the two electrodes was 0.001 meters. In future experiments the gap distance between the electrodes and the ULSD flow rate will be varied. Also, future experiments will be conducted with continuously applied electric potential.

Water droplet contact angles were measured on the coated discs prior to the coalescence experiments. Using a Drop Shape Analyzer (DSA20E, Krüss GmbH, Germany) the zero potential contact angles were measured at a radial distances of $0.005 \mathrm{~m}, 0.01 \mathrm{~m}$ and $0.013 \mathrm{~m}$ from the center of the disc at four positions around the circumference of the discs. The 


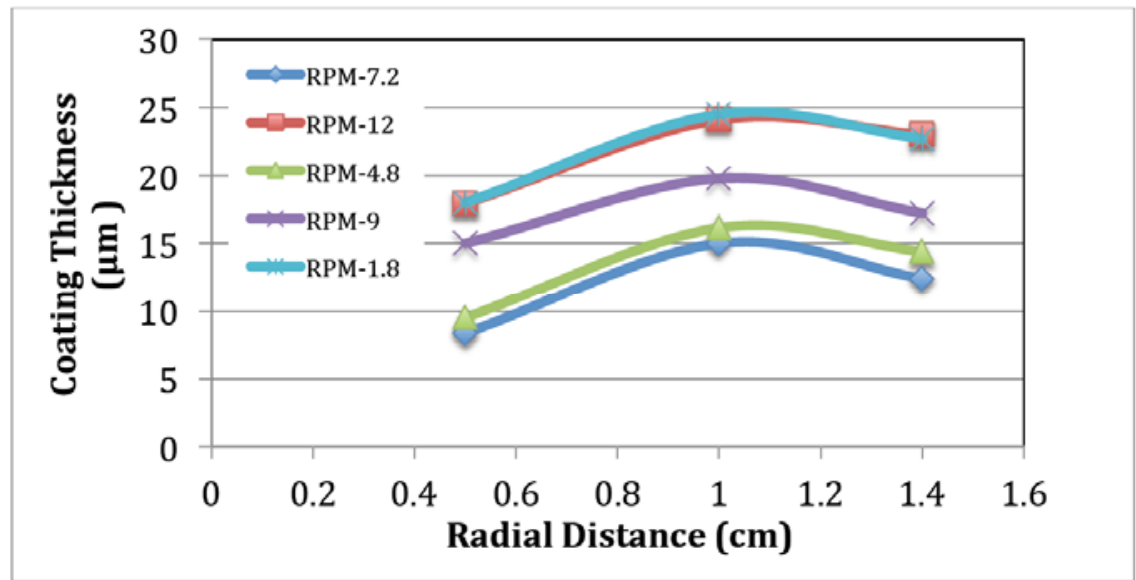

Figure 7: Variations in coating thicknesses with radial positions. The PS/PMMA solution concentrations were $15 \mathrm{wt} / \mathrm{wt} \%$, rotation rates were 7.2 RPM, and immersion times were $15 \mathrm{sec}$. The drying times were one day.

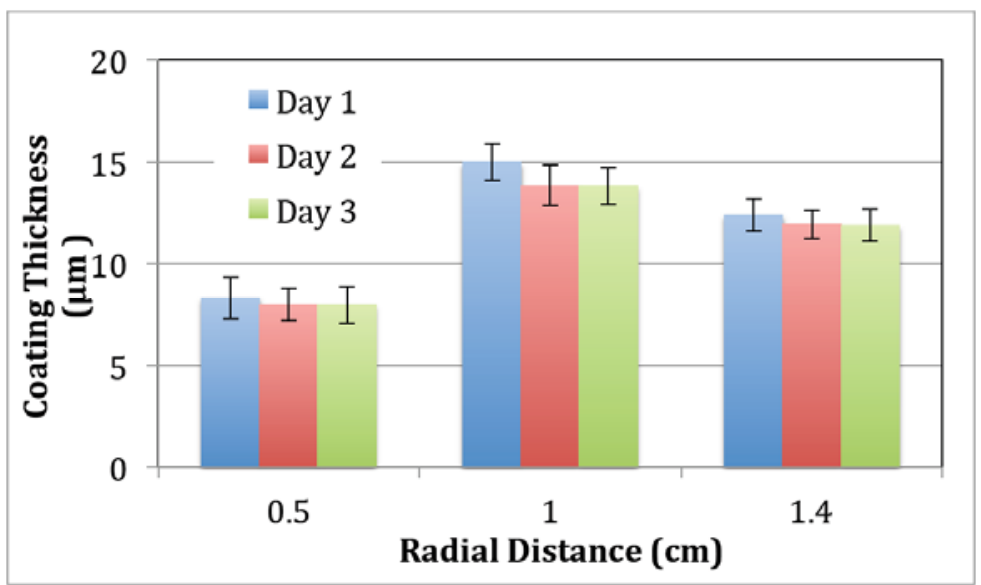

Figure 8: Coating thicknesses at different radial positions on the discs and for different drying times.

contact angles were $116 \pm 1$ deg. In a sequence of five experiments the discs were removed after each experiment and the zero potential contact angles were re-measured and found to be consistently $114 \pm 2$ deg, suggesting that the coatings were re-usable. More experiments are needed to determine their durability for long term.

The potentials previously determined to cause movement the 0.5 microliters drops were specific to that drop size in that electrode geometry. The two disc electrode geometry with coatings on both discs was expected to require a larger potential to cause drop movement. Also smaller drops initially not in contact with the two electrodes were expected to require a larger applied potential to cause coalescence. Hence the coalescence experiments were conducted at applied potentials greater then $160 \mathrm{~V}$ and less than the breakdown voltage of the dielectric material of $480 \mathrm{~V}[28,29]$. The power supply could generate potential differences up to $400 \mathrm{~V}$. Hence potentials of $300 \mathrm{~V}$ and $350 \mathrm{~V}$ were selected to compare with the blank run at $0 \mathrm{~V}$.

All coalescence experiments were operated with flow rates of $4 \mathrm{ml} / \mathrm{s}$ and fixed gap distance between discs of $0.001 \mathrm{~m}$. The applied electric potentials of 300 or 350 volts were turned on or off every 60 seconds.

Figure 9 shows the drop size distributions (droplet count per volume vs droplet diameter in micrometers) upstream and downstream at times 20,40, and 60 seconds in the experiment when no potential difference was applied to the discs. The upstream size distributions were very steady and consistent over time as were the downstream size distributions. The average upstream size was about 33 microns and the downstream average size was about 40 microns, showing a modest increase in drop size.

The total masses of the upstream and downstream distributions were calculated from the number counts of each drop size. In all of the experiments the differences between the calculated total masses were less than $10 \%$ error relative to the upstream and hence showed good closures on the total mass balances. In Figure 9 the increased mass of water corresponding to the increased the number of drops from upstream to downstream in the size range of about 70-100 microns was balanced by the decreased mass corresponding 


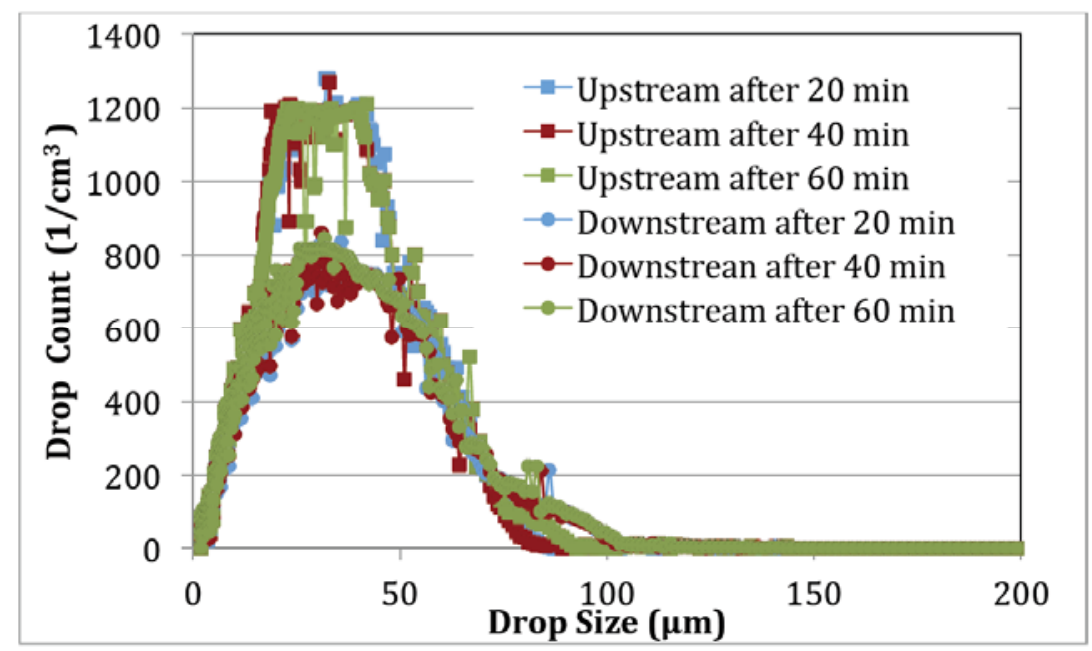

Figure 9: Coalescence experiment with zero applied potential. The average drop sizes were about 33 and 40 microns upstream and downstream respectively.

to the decreased numbers of drops in the size range of 20 to 60 microns.

Figure 10 shows similar drop size distributions but with applied potential difference of $300 \mathrm{~V}$ between the electrodes. The average outlet drop size was about 90 microns with most drops in the range of 65 to 115 microns. The total number of downstream drops significantly reduced due to the coalescence and was consistent with the total mass balance.

Figure 11 shows the distributions for experiments conducted at 350 volts. The average downstream drop size was about 107 microns with most of the drops in the range of 80 to 150 microns.

Figure 12 summarizes the results by plotting the average downstream drop sizes versus the applied potentials. As the potentials increased the average drop size increased, showing the electrowet-coalescer was very effective in increasing the drop size.
The electrowet-coalescer enlarged the drops but did not actually separate the drops from the ULSD. A downstream device must be operated with the electrowet-coalescer to achieve the actual separation. This work demonstrates the proof of concept. Future work is needed to study the performance of the electrowet-coalescer with downstream separators. Future work should also consider optimization of the coatings on the disc surfaces and explore other parameters of the electrowet-coalescer such as continuous applied electric potential and variations in the gap between the electrodes.

\section{SUMMARY AND CONCLUSION}

Stainless steel discs surfaces were coated with dielectric and hydrophobic materials for electrowetting. The discs were rotated as they were dipped into the coating solutions and the coating thicknesses varied with radial position. Immersion times, rotation rates, and dielectric solution concentrations

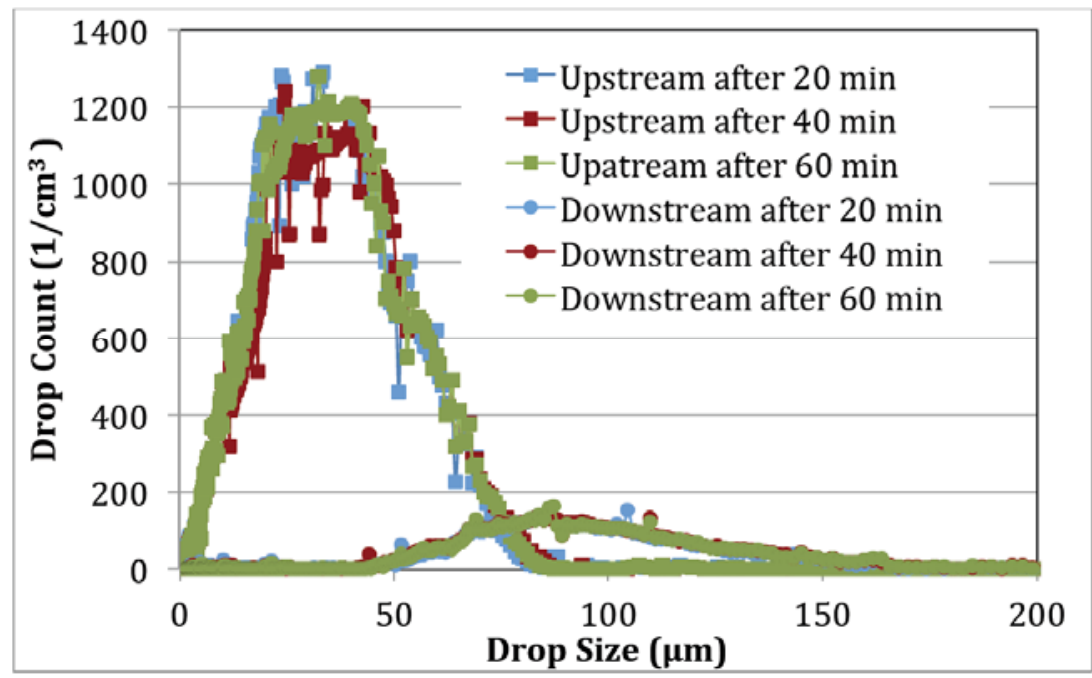

Figure 10: Coalescence experiment with applied potential $300 \mathrm{~V}$ turned on and off every 60 seconds. The average drop sizes were about 33 and 90 microns upstream and downstream respectively. 


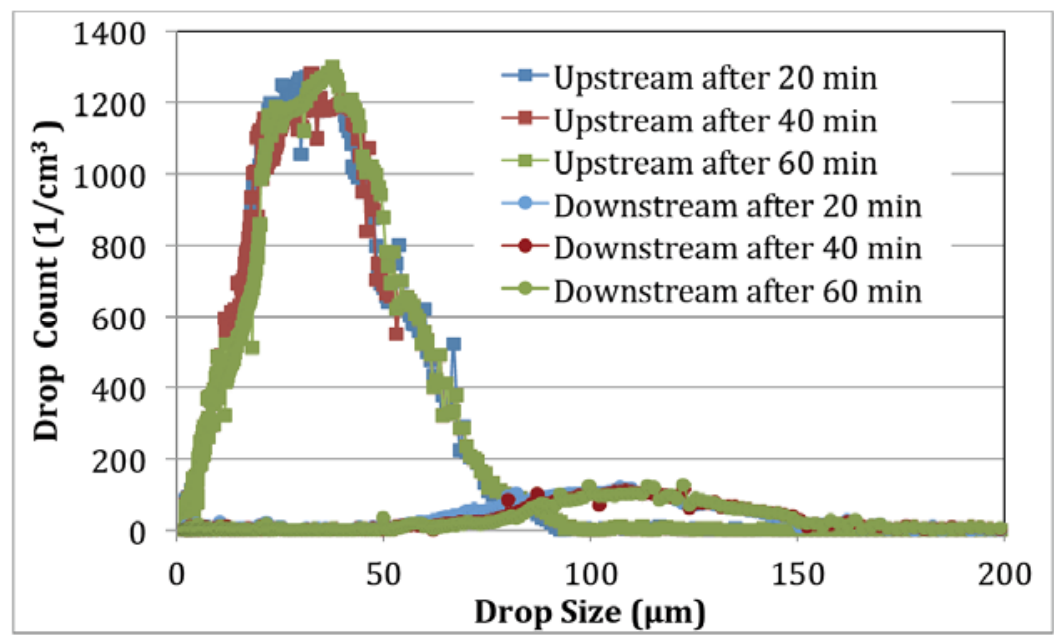

Figure 11: Coalescence experiment with applied potential $350 \mathrm{~V}$ turned on and off every 60 seconds. The average drop sizes were about 33 and 107 microns upstream and downstream respectively.

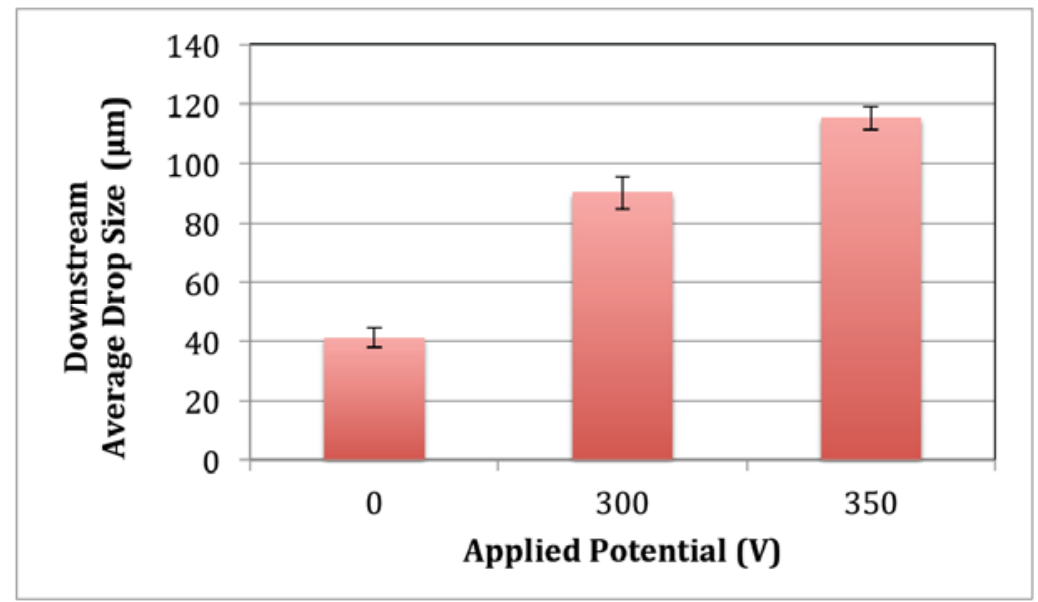

Figure 12: Average downstream drop size vs. applied potential.

were studied. Coatings were created for which 0.5 microliter drops moved when charged to $160 \mathrm{~V}$.

The coated discs were tested in an electrowet-coalescer device. When charged to $350 \mathrm{~V}$ the coalescence of the water drops in the ULSD emulsions increased in average drop sizes from 33 to 107 microns, showing significant coalescence of the water drops.

The electrowet-coalescer device has potential for use as a pre-treatment device to enhance effectiveness of waterULSD separation filters. Further study is needed to optimize design and operation of the electrowet-coalescer.

\section{REFERENCES}

[1] Vladisavljevic GT, Schubert STH. Preparation of water -in-oil emulsions using microporous polypropylene hollow fibers: influence of some operating parameters on droplet size distribution. Chemical Engineering and Processing: Process Intensification 2002; 41(Issue3): 231-238.

[2] Liu M, Li J, Guo Z. Polyaniline coated membranes for effective separation of oil-in-water emulsions. Journal of Colloidal and Interface Science 2016; 467: 261-270. http://dx.doi.org/10.1016/j.jcis.2016.01.024

[3] Patel SU, Chase GG. Seperation of water droplets from water- inULSD dispersion using superdydrophobic polypropylene fiborous membranes. Seperation and Purification Technology 2016; 126: 6268.

http://dx.doi.org/10.1016/j.seppur.2014.02.009

[4] Eow JS, Ghadiri M, Sharif AO, Williams TJ. Chemical Engineering Journal 2001; 84(3): 173-192. http://dx.doi.org/10.1016/S1385-8947(00)00386-7

[5] Eow JS, Ghadiri M. Drop-drop coalescence in an electric field: the effects of applied electric field and electrode geometry. Colloids and Surfaces A: Physicochem . Engineeing Aspects 2003; 219: 253-279. http://dx.doi.org/10.1016/S0927-7757(03)00051-7

[6] Taylor SE. Investigations into the electrical and coalescence behavior of water-in-crude oil emulsions in High voltage gradients. Colloids and Surfaces 1998; 29: 29-51.

http://dx.doi.org/10.1016/0166-6622(88)80170-7

[7] Sample SB, Raghupathy B, Hendricks CD. Quiescent distortion and resonant oscillations of a liquid drop in an electric field. Int J Eng Sci 1970; 8: 97-109. http://dx.doi.org/10.1016/0020-7225(70)90017-0

[8] Taylor SE. Theory and practice of electrically enhanced phase separation of water-in-oil emulsions. Chem Eng Res Des 1996; 74 526-540.

[9] Zhang Y, Liu Y, Ji R, Wang F, Cai B, Li H. Application of variable frequency technique on electrical dehydration of water-in-oil emulsion. Colloids and Surfaces A: Physicochemical and Engineering Aspects 2011; 386: 185-190.

http://dx.doi.org/10.1016/j.colsurfa.2011.07.010 
[10] Scott WT. Analytic studies of cloud droplet coalescence I. Journal of the Atmospheric Sciences 1968; 25(Issue 1).

[11] Yarin AL, Liu W, Doiphode SV, Chase GG, Reneker DH. Liquid Drop Growth on a Fiber. AICHE J 2006; 52(1): 217-227. http://dx.doi.org/10.1002/aic.10661

[12] Family F, Meakin P. Kinetics of droplet growth process: Simulations, theory, and experiments. American Physical society Journal- Physical Review 1989; 40: 3836-3854.

http://dx.doi.org/10.1103/PhysRevA.40.3836

[13] Adamson AW, Gast AP. Physical Chemistry of Surfaces, $6^{\text {th }}$ ed., Wiley, New York, 1997.

[14] Quilliet C, Berge B. Elecectrowetting: a recent outbreak. Current Opinion in Colloid and Interface Science 2001; 6(Issue 1): 34-39. http://dx.doi.org/10.1016/S1359-0294(00)00085-6

[15] Daniel S, Chaudary MK, Chen JC. Fast drop movements resulting from the phase change on a gradient surface. Science 2001; 291(pt5504): 633-636. http://dx.doi.org/10.1126/science.291.5504.633

[16] Lee J, Moon H, Fowler J, Schoellhammer T, Kim C-J. Electrowetting and electrowetting-on-dielectric for microscale liquid handling. Sensors and Actuators A: Physical 2002; 95(Issues2-3): 259-268. http://dx.doi.org/10.1016/S0924-4247(01)00734-8

[17] Yi U-C, Kim C-J. Characterization of electrowetting actuation on addressable single-side coplanar electrodes. Journal of Micromechanics and Microengineering 2006; 16: 2053-2059. http://dx.doi.org/10.1088/0960-1317/16/10/018

[18] Papageorgiou D, Tserepi A, Boudouvis A, Papathanasiou A. Superior performance of multilayered fluropolymer films in low voltage electrowetting. Journal of Colloid and Interface Science 2012; 368: 592-598. http://dx.doi.org/10.1016/i.jcis.2011.10.035

[19] Wei D, Zhao Y-P. An Electrowetting Model for Rough Surfaces Under Low Voltage. Journal of Adhesion Science and Technology 2008; 22 : 217-229.

http://dx.doi.org/10.1163/156856108X306966
[20] Kim JY, Seo JH, Leeetal JH. Fabrication and Characterization of electrowetting on the flexible substrate. Publication of Material Research Society 2007; 1004.

[21] Frieder B, Mugele J-C. Electrowetting: from Basics to Applications. Journal of Physics: Condensed Matter 2005; 17: 705-74. http://dx.doi.org/10.1088/0953-8984/17/28/R01

[22] Mugele F. Fundamental challenges in electrowetting: from equilibrium shapes to contact angle saturation and drop dynamics. Soft Matter 2009; 5: 3377-3384. http://dx.doi.org/10.1039/b904493k

[23] Fair RB, Lin YY, Evans RD, Welch E, Hsu B, Madison A. Low voltage electrowetting-on-dielectri platform using multilayer insulators. Elsevier 2010; 150: 465-470.

[24] Berge B, Peseux J. Variable focal lens controlled by an external voltage: An application of electrowetting. The European Physical Journal E 2000; 3: 159-163. http://dx.doi.org/10.1007/s101890070029

[25] Hayes RA, Feenstra BJ. Video-speed electronic paper based on electrowetting. Nature 2003; 425: 383-385. http://dx.doi.org/10.1038/nature01988

[26] Adamson AW, Gast AP. Physical Chemistry of Surfaces, $6^{\text {th }}$ ed, Wiley, New York, 1997.

[27] Aljuhani AS, Chase GG. Electro-coalescence of water droplets in air medium by electrowetting. Society of Petroleum Engineers 2013.

[28] Jiang $\mathrm{H}$. The relationship between chemical structure and dielectric properties of plasma-enhanced chemical vapor deposited polymer thin films. Thin Solid Films 2007; 515: 3513-3520. http://dx.doi.org/10.1016/i.tsf.2006.10.126

[29] Samant SP, Grabowski CA, Kisslinger K, et al. Directed Self Assembly of Block Copolymers for High Breakdown Strength Polymer Film Capacitors. Applied Materials and Interfaces 2016; 8(pt-12): 7966-7976 